\title{
Evaluation of Hair Growth Promoting Activity of Maharanga bicolor and Hibiscus rosa sinensis
}

\section{${ }^{1}$ Kishor Adhikari, 'Laxman Wagle, ${ }^{1}$ Pramod Dhakal, ${ }^{1}$ Sanjaya Dhungana, ${ }^{1}$ Sujan Baral, ${ }^{1}$ Nirmala Jamarkattel-Pandit}

\author{
${ }^{1}$ School of Health and Allied Sciences, Pokhara University, Nepal
}

\begin{abstract}
Alopecia is common and most frequently complaint dermatological disorder since the time immemorial. Various herbal and allopathic formulations are reported to have hair growth promoting activity. Minoxidil and Finasteride are only US FDA approved drugs for alopecia and hair loss. Maharanga bicolor and Hibiscus rosa sinensis are two ethnomedicinal herbs commonly used for hair growth promotion. Present study was conducted to determine hair growth promoting activity of petroleum ether extract of $M$. bicolor and H. rosa sinensis in Aloe vera gel. Minoxidil Sulphate and Different formulations of petroleum ether extract of $M$. bicolor and H. rosa sinensis was formulated in Aloe vera gel and applied to denuated area of rats for 30 days. Hair growth pattern, hair growth initiation, hair growth completion and length of hair was measured. M. bicolor (2\%) formulation shows shortest hair growth initiation time on $6^{\text {th }}$ day compared to $11^{\text {th }}$ day in blank sample. Formulation containing $2 \%$ of each extract have shortest hair growth completion time on $19^{\text {th }}$ day of sample application and showed potent hair growth pattern observed by blind investigation. The result suggests that petroleum ether extract of $M$. bicolor and $H$. rosa sinensis possess good hair growth promoting activity.
\end{abstract}

Key words: Maharanga bicolor, Hibiscus rosa sinensis, Hair growth promotion, Activity

Corresponding address: Nirmala Jamarkattel-Pandit, $\mathrm{PhD}$, School of Health and Allied Sciences,

E-mail: nirmalajk@hotmail.com

\section{INTRODUCTION}

Alopecia is a condition of hair loss from some or all areas of the body usually from scalp. It has been recognized for more than 2000 years as common cosmetic problem. It is neither life threatening nor painful condition but is a common and most frequently encountered patient complaint due to significant psychological and physical distress. Among various types of alopecia Androgenic alopecia can occur in both men (male pattern baldness) and female (female pattern baldness) which is characterized by diffused hair loss in scalp. ${ }^{1}$ Androgenic alopecia results from conversion of the hormone testosterone into dihydrotestosterone (DHT) by enzyme 5-alpha reductase. Alopecia areata is highly unpredictable autoimmune disease that results in hair loss on scalp or on whole body. Depending upon the extent and nature of hair loss alopecia areata is further classified into alopecia totalis, alopecia universalis etc. Hair is terminally differentiated, dead keratinocytes which exerts a wide range of functions including thermoregulation, collecting sensory information, protection from environmental trauma, social communication and mimicry. ${ }^{2}$ Human body contains 5 millions of hair follicle of which around 80,000 to 150,000 hair follicles are in scalp. Hair grows in three cyclic phases of growth (anagen), regression (catagen), and rest (telogen). Approximately $85-90 \%$ of all scalp follicle hairs are within anagen follicles. Anagen lasts for 2-6 years, catagen last for a few weeks, followed by telogen phase which lasts for 2 to 4 months. Dysfunction of cycle in telogenic or anagenic phase results in hair loss. ${ }^{2}$ Nutrition and their proper balance play an important role in hair growth. It has been reported that various vitamins like A, C, E, B, folic acid, biotin, ect exerted supportive effect in hair growth and treatment. Two allopathic medicines namely Finasteride and Minoxidil which are approved by FDA for hair growth promotion but unwanted side effects were reported. Herbs have been the most important source of medicine since the time immemorial. It is generally believed that herbal drugs are cheaper, locally available and devoid of any side effect. ${ }^{3}$ Natural products and herbs are commonly used in various cosmeceuticals and pharmaceuticals. ${ }^{4}$ Commonly marketed herbal products are claimed to have hair tonic, hair growth promoter, hair conditioner, hair cleansing agent, antidandruff agents as well as for the treatment of alopecia and lice infection. Currently, about 1000 kinds of plant extract have been screened for hair growth. ${ }^{5}$ Plant derived medicines have been under investigation for hair growth promoting activities..$^{6,7}$ Many plants have been described as hair tonic in several texts of traditional medicine. ${ }^{8}$ Maharanga bicolor which is perennial herb distributed at an altitude of 2300$2700 \mathrm{~m}$ in Nepal, Bhutan, North-East India and west china, used for hair growth promotion in himalayan region..$^{9-11}$ Hibiscus rosa sinensis Linn. (Malvaceae) is glabrous ornamental perennial tropical herb commonly cultivated in tropical and subtropical regions of the world, ${ }^{12}$ is distributed in tropical and subtropical region all over the world ranging from 30 degrees north latitude to 30 degrees south latitude. $H$. rosa sinensis is used as medicine by every civilization in direct or indirect from ancient times. The main aim of the study was to evaluate hair growth promoting activity of $M$. bicolor and $H$. rosa sinensis. 


\section{MATERIAL AND METHODS}

\section{Crude drugs collection and Identification}

The leaves of Hibiscus rosa-sinensis Linn and rhizomes of $M$. bicolor were collected from Lekhnath, Kaski district and Marpha, Mustang respectively. Aloe vera gel was collected from Kaski district The crude drugs were identified in National Herbarium and Plant Laboratory, Godawari, Nepal comparing with standard herbarium specimens and with related literatures ${ }^{10}$

\section{Animal models}

Healthy Wister albino rats weighing between 120-150 g were used for in vivo hair growth studies. They were purchased from the Department of plant resources, Government of Nepal, Thapathali, Kathmandu, Nepal. The rats were placed in cage and housed at room temperature, fed with standard diet and water ad libitum.

\section{Extraction of crude drugs}

Dried powdered leaves, rhizomes was soxhlet extracted with petroleum ether till completely exhausted. Briefly powder were packed in thimble paper and placed in soxhlet apparatus for extraction. $130.28 \mathrm{~g}$ powder of M. bicolor and $215.20 \mathrm{~g}$ of $\mathrm{H}$. rosa sinensis in different lots were extracted with petroleum ether. Extraction was performed for 3 hours at $65^{\circ} \mathrm{C}$. Afte extraction, solution was filtered and evaporate by using vacuum evaporator for under reduced pressure. The yield value was calculated for each extract and that was stored in air tight container for further studies.

\section{Sample Preparation}

Firstly different formulation was designed for different extract in Aloe vera base. Formulation design consisted of two steps:

\section{1) Preparation of Aloe vera gel base}

Aloe vera gel was prepared as base for all the preparation. Collected fresh Aloe vera leaves was washed with distilled water. The Aloe vera gel was extracted from the leaves by a Filent method ${ }^{13}$. In this method, the anthraquinone containing yellow sap from the pericyclic cells was drained from the freshly cut leaves. The gel from these leaves was collected by means of longitudinal incision on the dorsal side of leaves and any foreign particles removed from the gel manually. To improve stability of the gel, it was heated to $40^{\circ} \mathrm{C}$ and then a blend of stabilizing agent consisting of ascorbic acid $(0.5 \% \mathrm{w} / \mathrm{w})$ and sodium benzoate $(0.5 \% \mathrm{w} / \mathrm{w})$ was added and mixed uniformly. The gel was then cooled to room temperature and stored in cool and dry place until use.

2) Preparation of test samples Nine different test samples with $2 \%$ and $5 \%$ extract of each $H$. rosa-sinensis Linn and $M$. bicolor was prepared in the Aloe vera base to obtain herbal gel formulation of each extract and mixture of extract was also made to prepare a polyherbal formulation as shown in Table 1. Two percent Minoxidil was used as positive control while blank formulation was considered as negative control.

The prepared formulation was evaluated for

1. Texture : Done by naked eye

2. Odor :smelled
3. Primary skin irritation Test: This test was conducted to evaluate the irritancy of prepared formulations on intact skin of rats. None of the formulation showed erythema or edema which indicated that prepared formulation was non irritant on the skin of rat.

\section{Application of test sample}

Hairs on dorsal side of the diethyl ether induced anesthetized animals were removed using small size scissors to assure the complete denude of $4 \mathrm{sq} \mathrm{cm}$ areas. Finally denuded skin was wiped off with surgical spirit. Equal quantity of $(0.5 \mathrm{ml})$ prepared sample and standard Minoxidil solution were applied topically to the denuded area of each groups rats (nine groups) for 30 days once a day. The sample was applied with the help of graduated droppers.

\section{Determination of hair growth initiation and completion time}

Hair growth initiation time i.e. minimum time to initiate perceptible hair growth and hair growth completion time i.e. minimum time taken to cover the denuded area with new hair completely was evaluated by visual observation of hair throughout dorsal surface of rats.

Blind investigation of extent of hair growth with questionnaire survey

The rats from different groups were randomly distributed and coded. Then a survey was conducted on $15^{\text {th }}$ day of sample application by calling the invigilator who were blind to the experiment and samples and asking them to observe the rats and fill the provided questionnaire sheet.

\section{Hair length Measurement}

The hair was plucked randomly from the shaved area of selected rats after $15^{\text {th }}$ and $30^{\text {th }}$ day of treatment. Length of 5 hairs of each rat from each group was measured with the help of Vernier caliper. The average length of hair was determined. Determination of this parameter has been considered as vital for accomplishment of hair growth. The results were expressed as the mean length $\underline{ \pm}$ SD. The results were compared among the different groups.

\section{Statistical analysis}

The data were reported as mean \pm SD of hair length. Statistical analysis of data is carried out by pair student t-test comparing all test groups versus controls with level of significance less than 5 $\%$.

\section{RESULTS}

Extract yield value

The percentage extract yield value of M. bicolor and H. rosa sinensis in petroleum ether extraction was $1.78 \%$ and $2.93 \%$ respectively.

Hair growth initiation and completion time

Hair growth initiation and completion time was found to vary among different groups (Figure 1). Hair growth initiation was observed on 6th day in $\mathrm{F} 1$ treated group followed by $7^{\text {th }}$ day in $\mathrm{F} 5$, F6, and F7 treated group which is considered as shorter period. In F3 and F4 treated groups, initiation time was delayed up to $8^{\text {th }}$ 
day whereas in F8 and F9 treated group, hair growth initiation were on $9^{\text {th }}$ and $11^{\text {th }}$ day of sample application respectively which is considered as longest period among the study. Hair growth completion was observed in all the rats within $26^{\text {th }}$ day of sample application. In F5 treated group it was on $19^{\text {th }}$ day of sample application which is considered as shortest period for hair growth completion. For F1 treated group it was found on $20^{\text {th }}$ day of sample application whereas in F71, F2 and F6 treated groups also, it took $21^{\text {st }}$ day of shorter period for hair growth completion. These groups are considered shorter period for hair growth completion. F2, F3 and F4 treated groups on the other hand, had longer hair growth completion time i.e. $23^{\text {rd }}$ day as compared to the F9 treated group which was the longest period for hair growth completion i.e. $26^{\text {th }}$ days of sample application.

\section{Blind investigation of extent of hair growth in different rats} under investigation

The 10 investigators unknown about the treatment to various rats observed the hair growth pattern and assigned them from A to $\mathrm{D}$ with $\mathrm{A}$ denoting the rats with excellent hair growth pattern (Marking 4), B denoting Good hair growth pattern (Marking 3), C denoting normal (Marking 2) and D denoting lesser comparatively (Marking 1). Higher the score obtained by each group, higher will be the hair growth pattern (Table 1). The results indicate that the hair growth pattern was different among the different groups. Among the treated groups, F5 treated groups had excellent hair growth pattern.

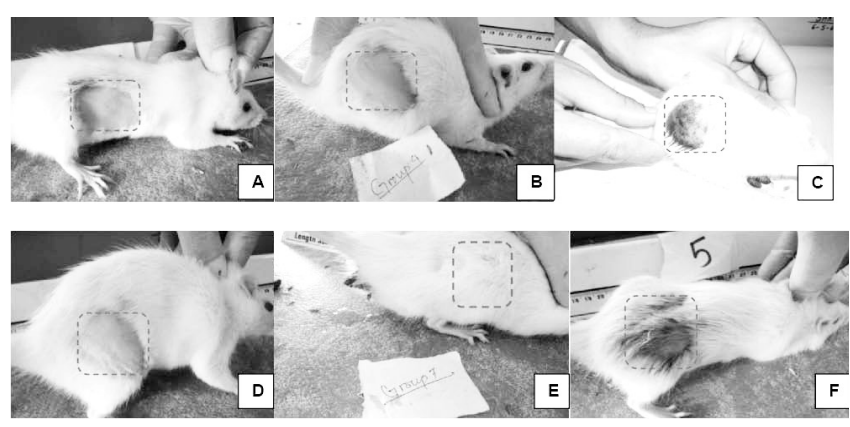

Figure 1: Hair growth initiation and completion time in various treated group

A: Denuded rat skin of group 9 at day 3

B: Denuded rat skin of group 4 at day 3

C: Application of formulation 1 to group 1 at day 3

D: Hair growth initiation in group 6 at day 7

E: completion of hair growth in group 7 at day 21

F: Hair growth completion in group 5 at day 18

\# $\mathrm{P}<0.05$ compared with blank control group

* $\mathrm{P}<0.05$ compared with Aloe vera gel only

\section{Hair growth Measurement}

The hairs were plucked randomly from all the rats of each group on $15^{\text {th }}$ and $30^{\text {th }}$ day of sample application. The improperly plucked hairs were discarded. The hair length was measured with the help of Vernier caliper which could read up to millimeter scale. Mean hair length of each group and standard deviation $\left({ }^{+} \mathrm{SD}\right)$ as measure of dispersion of hair length within each group was calculated and the result is presented in Table as shown below.

Table 1: Mean hair length and their score in various sample treated groups

\begin{tabular}{|c|c|c|c|}
\hline Group & Hair length $(\mathrm{cm}) 15^{\text {th }}$ day & Hair length $(\mathrm{cm}) 30^{\text {th }}$ day & Scoring \\
\hline $2 \%$ M. bicolor $(\mathrm{F} 1)$ & $1.51+0.11 \% \#$ & $1.96 \pm 0.16 * \#$ & $30.60 \pm 2.07$ \\
\hline $5 \%$ M. bicolor $(\mathrm{F} 2)$ & $1.27 \pm 0.22 \#$ & $1.84 \pm 0.07 * \#$ & $30.80 \pm 3.03$ \\
\hline $2 \%$ H. rosa sinensis $(\mathrm{F} 3)$ & $1.44 \pm 0.42$ & $1.90 \pm 0.15 * \#$ & $31.00 \pm 1.58$ \\
\hline $5 \%$ H. rosa sinensis $(\mathrm{F} 4)$ & $1.22+0.47$ & $1.70 \pm 0.11 \#$ & $30.40 \pm 2.70$ \\
\hline 2\% F1:F3 Formulation (F5) & $1.54 \pm 0.38 \#$ & $1.86 \pm 0.14 * \#$ & $33.20 \pm 1.30$ \\
\hline 5\% F2:F5 Formulation (F6) & $1.10 \pm 0.04 \#$ & $1.90 \pm 0.14 * \#$ & $31.80 \pm 1.64$ \\
\hline $2 \%$ Minoxidil (F7) & $1.13 \pm 0.03 \#$ & $1.76 \pm 0.06^{* \#}$ & $31.00 \pm 1.15$ \\
\hline \begin{tabular}{|l|} 
Aloe vera Gel only (F8) \\
\end{tabular} & $1.19 \pm 0.14$ & $1.48+0.17$ & $31.00 \pm 1.58$ \\
\hline Blank control (F9) & $0.73 \pm 0.11$ & $1.02 \pm 0.04$ & $25.33 \pm 2.30$ \\
\hline
\end{tabular}

$\# \mathrm{P}<0.05$ compared with blank control group

* $\mathrm{P}<0.05$ compared with Aloe vera gel only

\section{DISCUSSION}

In the present study the hair growth promoting activity of $M$. bicolor and $H$. rosa sinensis was performed using animal model. The plants were selected on the basis of their ethnomedicinal uses. Different plant extract formulation ratios were made by incorporating them in Aloe vera gel used as a vehicle and applied to denude skin of rats for one month where Minoxidil FDA approved drug was used as positive control. The measurement of hair length was done in $15^{\text {th }}$ and $30^{\text {th }}$ day of sample application.

The hair growth initiation time as well as hair growth completion time over the denuded skin of rats was observed during the course of study. Hair growth initiation time was started from $6^{\text {th }}$ to $11^{\text {th }}$ day of sample application which was observed earlier i.e. $6^{\text {th }}$ day in $2 \% M$. bicolor $(\mathrm{F} 1)$ treated group and later in $11^{\text {th }}$ day in blank treated group whereas other groups (F2, F3, F4, F5, F6, F7 and F8) shows initiation time at $7^{\text {th }}, 8^{\text {th }}, 8^{\text {th }}, 6^{\text {th }}, 7^{\text {th }}, 7^{\text {th }}$ and $9^{\text {th }}$ days respectively which indicates that hair growth initiation time was shorter in $2 \%$ M. bicolor (F1), 5\% M. bicolor (F2) and 5\% 1:1 mixture of M. bicolor and H. rosa sinensis (F5), than that of standard i.e. Minoxidil (F7).

Similarly the hair growth completion was observed from $18^{\text {th }}$ day to $26^{\text {th }}$ day of sample application which was observed earlier i.e. $18^{\text {th }}$ day in $2 \% 1: 1$ formulation (F5) treated group and later i.e. $27^{\text {th }}$ day in blank treated group (F9) whereas other formulations F1, F2, F3, F4, F6, F7 and F8 shows completion time at $19^{\text {th }}, 21^{\text {th }}, 23^{\text {rd }}, 21^{\text {th }}, 21^{\text {th }}, 23^{\text {rd }}$ and $27^{\text {th }}$ days respectively. Among these group 2\% 1:1 mixture of $M$. bicolor and $H$. rosa sinensis (F5), $2 \%$ M. bicolor (F1), 5\% M. bicolor (F2) and 5\% 1:1 mixture of M. bicolor and $H$. rosa sinensis (F6) shows better result as compared to standard Minoxidil (F7). Though, the initiation time of $2 \%$ M. bicolor (F1) is earlier, it has longer completion time in comparison to 2\% 1:1 mixture of $M$. bicolor and $H$. rosa sinensis (F4). This results indicates among the studied sample, $2 \% \mathrm{M}$. bicolor is superior for hair growth initiation and $2 \% 1: 1$ mixture of $M$. 
bicolor and H. rosa sinensis (F5) is superior for hair growth completion over the denuded area of rats skin which is also suported by blind investigations. Lenght of hair measure on $15^{\text {th }}$ and $30^{\text {th }}$ day of sample application shows that all sample treated groups showed potent activity as compared to control treated groups. On 15th day of sample application, F5 group has longest hair length followed by F1 and F3 which were stastically significant as compared to F8 group. In $2^{\text {nd }}$ observation ie 30th day of sample application, except F4, other group shows statistically significant with compare to Aloe vera gel treated group. The order of mean hair length in second observation treated groups was as: F1, F3, F6, F5, F2, F7, F4, F8 and F9. Though the mean hair length of the two observations shows better growth than control groups, only $2 \% \mathrm{M}$. bicolor shows the statistically significant result against Aloe vera gel in both observations. Also 1:1 ratio of both $2 \%$ plant extract has comparative result than rest of groups and single plant extract treated group which indicates that there may be the synergistic effect of both plant extracts in hair growth promotion. Aloe vera gel which was used as vehicle also shows promising hair growth activity against blank control. On the basis of this results, we can assum that these crude drugs might contain active chemical constituents that may act as hair growth promoter. Various studies had reported that presence of chemical constituents like diterpenes, carbohydrates and amino acids, glycosides, fats, have shown to promote hair growth activity. ${ }^{13,14}$ Some of the phytoconstituents which have been investigated for hair growth promoting activity are proanthocyanidins, 3,4 dimethyl 3-hydroxy flavanone, ginsenoside from red ginseng, and active principles of Polygara senega such as senigose A, senegin II, III and senega saponin $\mathrm{B}^{15,16}$. Thus it can be suggested that the hair growth promoting activity of $M$. bicolor and $H$. rosa-sinensis could be due to the single and synergistic effects of active phytoconstituents.

It has been reported that the minoxidil induces proliferation of epithelial cells near the base of the hair follicle and may induce the vasodilation of scalp blood vessels. Minoxidil shorten telogen phase thus causing premature entry of resting hair follicles into anagen phase. According to Messenger et.al., the effect of Minoxidil on hair growth is due to the opening of potassium channels by Minoxidil sulphate. ${ }^{17}$ Minoxidil may also prolong the anagen phase and increase hair follicle size. According to Roy et.al., the petroleum ether extract treatment may have caused premature switching of hair follicles from resting telogen phase to active anagen phase ${ }^{18}$. In our present study, hair growth initiation, completion and hair length of $2 \% M$. bicolor extract and its equal mixture with $H$. rosa sinensis extract treated group is superior than Minoxidil which indicates that these plant extracts may have potential hair growth promoting activity. However, the exact mechanism of such extracts on hair growth has not been clear. The petroleum ether extract of M. bicolor when prepared 2 and 5\% extract formulation in Aloe vera gel the formulation was blood red in color. The application of these formulation imparted red color to the hairs of albino rats which justifies its local name "Maharangi" which means superior in color. Thus, the rhizome of M. bicolor could also be useful for hair coloring as well.

Finally, it is concluded that the rhizome extract of M. bicolor and leaf extract of $H$. rosa-sinensis has a potential effect on maintaining the hair growth and it is suggested that the rhizome extract of M. bicolor and leaf extract of $H$. rosasinensis could be included as a constituent in the hair growth formulations.

\section{CONCLUSION}

The present study provides a support to the traditional claim that M. bicolor and H. rosa sinensis acts as hair growth promoter. Also Aloe vera gel is a hair growth promoting substance. Identification and isolation of molecules from the extract may provide new directions for the treatment of hair loss. Further elucidation of mechanism of action for the extract will act as milestone to prove the activity.

\section{REFERENCES}

1. Kimura-Ueki M, Oda Y, Oki J. Hair Cycle Resting Phase Is Regulated by Cyclic Epithelial FGF18 Signaling. J Invest Dermatol, 2012; 132(5):1338-45.

2. Krause K, Foitzik K. Biology of Hair Follicle: The Basics, Seminars in Cutaneous Medicine and Surgery. 2006; 25:2-10.

3. Pal SK, Shukla Y. Herbal Medicine: Current Status and the future. Asian Pacific J Cancer Prev, 2003; 4:281-288.

4. Takahashi T, Kamiya T, Yokoo Y. Proanthocyanidines from grape seeds promote proliferation from hair follicle cells in vitro and convert hair cycle in vivo. Acta Derm Venereol, 1998; 78:428-432.

5. Thorat RM. Herbal Treatment for hair loss, Int. Journal of Pharmacy and Technol, 2010; 2(4):497-503.

6. Adhirajan N, Kumar TR, Shanmugasundaram N, Babu M. In vivo and in vitro evaluation of hair growth potential of $\mathrm{H}$. rosa sinensis Linn. J Ethnopharmacol, 2003; 88:235-239.

7. Awe EO, Makinde JM. The hair growth promoting effect of Russelia equisetiformis. J. Natur Products, 2009; 2:70-73.

8. Gewali MB. Aspects of Traditional Medicine in Nepal, Institude of Medicine, Institute of Natural Medicine, University of Toyama, Toyama, Japan, 2008; 119.

9. Zhang e zi cao shu. Maharanga, Flora of China, 1995; 16:346-348. 
10. Manandhar NP. Plants and People of Nepal. Timber Press, Portland, Oregon, 2002. 599. ISBN: 0-88192-527-6

11. Bhattarai S, Chaudhary RP, Taylor RSL. Ethanomedicinal plants used by the people of Manage district, central Nepal, J. Ethanobio. Ethanomed, 2006; 2:41

12. Upadhyay S, Upadhyay P. H. rosa sinensis: Pharmacological review, Int Journal of Res. in Pharma.Biomedi. Sci, 2011; 2(4):1449-1450.

13. Matsuda H, Yamazaki M, Asanuma Y, Kubo M. Promotion of hair growth by ginseng radix on cultured mouse vibrissal hair follicle. Phytotherapy Res, 2003; 17(7):797-800.

14. Jadhav VM, Thorat RM, Kadam VJ, Gholve SB. Kesharaja: Hair vitalizing herbs. Inter. Journal of PharmTech.Research, 2009; 1:454-467.

15. Takahashi T, Kamiya T, Yokoo Y. Procyanidin oligomers selectively and intensively promote proliferation of mouse hair epithelial cells in vitro and active hair follicle growth in vivo. J Invest Dermatol, 1999; 112:310-16.

16. Ishida H, Inaoka Y, Okada M, Fukushima M, Fukazawa H, Tsuji K. Studies of the active substances in herbs used for hair treatment. III. Isolation of hair-regrowth substances from Polygara senega var. latifolia TORR et GRAY. Biol Pharm Bull, 1999; 22:1249-50.

17. Messenger AG. Medical management of male pattern hair loss. Int. J. Dermatol, 2000; 39:585- 586.

18. Roy RK, Thakur M, Dixit VK. Effect of Citrullus colocynthis on hair growth in albino rats. Pharma. Biol, 2007; 45(10):739-744. 